\title{
O Programa Pró-Equidade de
}

Gênero: uma experiência de política

pública para a promoção da igualdade

de oportunidades e tratamento /

Gender Pro-Equity Program: a public policy

experience towards the promotion of equal

opportunities and treatment

Resumo: Os alcances da primeira edição do Programa PróEquidade de Gênero, implementado no contexto do Plano Nacional de Políticas para as Mulheres (PNPM), são apresentados e discutidos como instrumento de promoção da igualdade de gênero em grandes empresas públicas do setor eletro-energético. O programa, coordenado pela Secretaria Especial de Políticas para as Mulheres da Presidência da República, é uma iniciativa do governo federal, mas está baseada na adesão voluntária das empresas. A análise tem como base, o exame de documentos produzidos pela Secretaria e pelas empresas participantes do Programa e as entrevistas em profundidade com gestoras da SPM e membros dos Comitês de Gênero das empresas participantes. Em alguns casos, os planos de ação das empresas abrangeram suas cadeias de relacionamento, formadas por outras empresas de diferentes tipos e tamanhos; em outros, incluíram a promoção da igualdade racial em articulação com a questão da igualdade de gênero.

Palavras-chave: gênero, igualdade de oportunidades, políticas públicas, Brasil.

Abstract: This text aims to present and discuss the outcomes of the Gender Pro-Equity Program, a federal initiative developed

Mestre e doutora em Sociologia pela Universidade de São Paulo (USP); diretora do Escritório da Organização Internacional do Trabalho (OIT) no Brasil. E-mail: abramo@oitbrasil.org.br 
within the National Plan for Policies on Women, under the coordination of Presidency of Republic's Special Secretariat for Policies on Women. The Program, a non regulatory measure at enterprise level, is a tool for the gender equality promotion in big public enterprises. The analysis carried out in this article focus on the Program's 1st edition, which took place from September 2005 to December 2006. Apart from some Secretariat's and enterprises' documents, it also took into account in depth interviews with the enterprises' gender committees members and Secretariat's officials. In some cases, the enterprises action plans comprehended their relationship chains, in other cases, they comprehended the promotion of racial equality in combination with the gender equality issue.

Key words: gender, equal opportunities, public policies, Brazil.

O objetivo desse texto é apresentar e discutir o programa Pró-Equidade de Gênero, que vem sendo implementado no contexto do Plano Nacional de Políticas para as Mulheres (PNPM), principal instrumento do governo federal para promover a transversalização de gênero nas políticas públicas. Ao lado das ações de fiscalização do trabalho e do esforço de capacitação dos auditores fiscais das Superintendências Regionais do Trabalho (antigas Delegacias Regionais do Trabalho), parte integrante do objetivo mais geral de capacitar os gestores públicos de diversas áreas do governo federal nos temas de gênero, o Pró-Equidade é o principal programa do PNPM dirigido à promoção da igualdade de gênero nas empresas do setor formal.

A análise desenvolvida neste artigo centra-se na primeira edição do Pró-Equidade de Gênero, que se desenvolveu de setembro de 2005 a dezembro de 2006, já que a sua segunda edição ainda está em curso. Além do exame de documentos produzidos pela Secretaria Especial de Políticas para as Mulheres (SPM) e pelas empresas participantes do Programa, tem como base entrevistas em profundidade com gestoras da SPM e membros dos Comitês de Gênero das empresas participantes do Programa. ${ }^{1}$ Apesar do

Uma análise mais detalhada pode ser encontrada em Abramo (2007, capítulo 8). 
pouco tempo de existência do Pro-Equidade, o que dificulta uma avaliação conclusiva acerca de seus resultados, o registro e a análise da experiência podem contribuir para uma discussão mais geral sobre as potencialidades e limites das políticas e programas que vêm sendo atualmente implementados no país com o objeitvo de promover os direitos das mulheres e da igualdade de gênero no âmbito do trabalho.

\section{Antecedentes e contexto}

Em 2003, o governo do presidente Luis Inácio Lula da Silva inaugura-se com uma novidade: a criação da Secretaria Especial de Políticas para as Mulheres (SPM), diretamente vinculada à Presidência da República. Dois meses depois (março de 2003), cria-se também a Secretaria Especial de Políticas de Promoção da Igualdade Racial (Seppir), respondendo a uma forte pressão do movimento negro no país. A missão das duas secretarias passa a ser basicamente a de transversalizar as dimensões de gênero e raça nas políticas públicas. ${ }^{2}$

A experiência recente dos países latino-americanos indica que os momentos de mudança governamental são críticos para a sobrevivência e/ ou o fortalecimento dos mecanismos de promoção da igualdade de gênero ou dos direitos da mulher (Montaño, 2003). ${ }^{3}$ Não são poucos os países que viram a institucionalidade de gênero desaparecer ou debilitar-se após uma mudança governamental, embora o processo inverso também tenha ocorrido. Esse foi o caso do Chile no momento de restauração da democracia (começo

\footnotetext{
2 A SPM foi criada por meio da Medida Provisória $n^{\circ} 103$ ( $1^{\circ}$ de janeiro de 2003), posteriormente convertida na Lei $\mathrm{n}^{\circ} 10.683$ (28 de maio de 2003). Entre as suas funções estão as de assessorar diretamente o presidente da República na formulação, coordenação e articulação de políticas para as mulheres; elaborar o planejamento de gênero; promover a igualdade de gênero e articular, promover e executar programas de cooperação com organismos nacionais e internacionais voltados para a implementação de políticas para as mulheres.

3 Esses mecanismos podem ser ministérios, secretarias, institutos, com diferentes tipos de mandato, orçamento e localização dentro do aparelho de Estado.
} 
dos anos 1990), quando foi criado o Serviço Nacional da Mulher (Sernam) e também do Brasil, no início da gestão do presidente Lula, quando foi criada a SPM, diretamente vinculada à Presidência da República.

Com efeito, a criação da SPM e da Seppir em 2003 marca o momento em que o Estado brasileiro começa a compensar o considerável atraso relativo do país em relação à constituição de uma institucionalidade para a promoção da igualdade de gênero vinculada ao Poder Executivo.

Em um contexto de transição e fortalecimento da democracia no Continente, e principalmente após a realização da IV Conferência Internacional da Mulher em Pequim (1995), mecanismos desse tipo haviam sido criados e/ou fortalecidos em muitos países da América Latina. Apesar de uma série de problemas bastante comuns por eles enfrentados no que se refere à sua capacidade de influenciar a agenda pública e mesmo a agenda interna de governo, de contar com orçamento e dotação de pessoal adequados, garantir a sua institucionalização e a interlocução com os outros ministérios e com a sociedade civil organizada, os avanços em alguns desses países haviam sido bastante mais significativos do que aqueles ocorridos no Brasil. Dessa forma, o que é inédito no quadro político brasileiro, na verdade é um caminho que já vinha sendo trilhado há bastante mais tempo em vários outros países latino-americanos. ${ }^{4}$

A criação da SPM foi uma resposta a uma antiga reivindicação do movimento de mulheres. Pode ser considerada o principal avanço institucional do primeiro mandato do governo Lula no âmbito da promoção da igualdade de gênero e um impulso importante para o fortalecimento do tema nas políticas públicas, assim como para a possibilidade de concretização de outros avanços institucionais

4 A criação da Seppir, por sua vez, pode ser considerada ao mesmo tempo como uma expressão e a criação de novas condições para o desenvolvimento de algo que, aí sim, coloca o Brasil em uma posição de vanguarda no contexto latino-americano, ou seja, o imbricamento da questão de gênero com a questão étnico-racial no âmbito das políticas públicas. 
que marcaram o período: a realização da I Conferência Nacional de Políticas para as Mulheres, a elaboração do I Plano Nacional de Políticas para as Mulheres, a multiplicação de organismos de políticas para as mulheres no âmbito dos governos estaduais e municipais ${ }^{5}$ e o fortalecimento, ainda que insuficiente, do tema no Plano Plurianual de Governo (PPA) 2004-2007. ${ }^{6}$

A criação da SPM constitui assim uma iniciativa importante do governo federal brasileiro no sentido de assumir um papel mais relevante na promoção da igualdade de gênero. Com isso, além de abrir caminho para uma ampliação da presença dessa perspectiva nas políticas públicas, contribui também para delimitar mais claramente a diferença entre o papel do Estado, do governo e o dos movimentos sociais de mulheres. Esse tema aparece claramente nas palavras de uma das entrevistadas:

Até então, havia no movimento de mulheres uma confusão entre o que era uma politica pública para as mulheres e o que era uma ação de controle social. Até então a coisa funcionava naquele modelo dos conselhos, sem equipe e sem independência orçamentária ${ }^{7}$. Portanto, criar a Secretaria e fazer essa distinção clara entre o que é um conselho e o que é um organismo estatal de promoção da igualdade foi algo muito importante e um grande avanço em um debate que vinha sendo feito bá pelo menos duas décadas.

\section{A instituição do Programa Pró-Equidade de Gênero}

O Programa Pró-Equidade de Gênero foi instituído pela Secretaria Especial de Políticas para as Mulheres (SPM) através da Portaria n ${ }^{\circ} 39$, de 22 de setembro de 2005, em cumprimento ao I Plano Nacional de Políticas para as Mulheres (PNPM). Seus objetivos foram definidos como: contribuir para a eliminação

\footnotetext{
5 O número de organismos de políticas para as mulheres nos executivos estaduais e municipais brasileiros passou de 13, em 2003, para 125, em 2006.

6 Ver discussão a respeito em Bandeira e Vasconcelos (2002), Agende (2003) e Abramo (2007 capítulo 7).

7 Com exceção do Conselho Nacional dos Direitos da Mulher, no curto período transcorrido entre os anos 1985 e 1989.
} 
de todas as formas de discriminação no acesso, remuneração, ascensão e permanência no emprego; conscientizar e sensibilizar empregadoras/es; estimular as práticas de gestão que promovam a igualdade de oportunidades entre homens e mulheres dentro das empresas; desenvolver novas concepções em termos da gestão de pessoas e da cultura organizacional e construir um banco de "boas práticas" de promoção da eqüidade de gênero no mundo do trabalho (Brasil-SPM, 2006b).

O programa tem sido desenvolvido em parceria com a Organização Internacional do Trabalho (OIT) e o Fundo de Desenvolvimento das Nações Unidas para a Mulher (Unifem), e sua primeira edição (2005/2006) esteve voltada para as empresas públicas e de economia mista. Dezesseis empresas assinaram o Termo de Adesão ao programa e, dessas, as onze que formularam um Plano de Ação e cumpriram as metas nele estabelecidas, receberam o selo Pró-Equidade de Gênero no final do período estipulado.

O programa se baseia no princípio de adesão voluntária das empresas. Esse tipo de iniciativa foi destacado como uma das formas importantes de combate à discriminação e promoção da igualdade de gênero no segundo Relatório Global da OIT (2007), relativo ao tema. Distingue-se das ações de responsabilidade social corporativa pelo fato de ser um programa estruturado a partir do governo federal, mais especificamente pela Secretaria Especial de Políticas para as Mulheres, no âmbito do PNPM. ${ }^{8}$ Entre as características principais de sua metodologia de implementação estão o comprometimento da alta direção das empresas, a elaboração de um plano de ação voluntário a partir de um autodiagnóstico realizado através de uma "ficha-perfil, ${ }^{9}$ e

\footnotetext{
8 O PNPM, por sua vez, é um plano que envolve a participação efetiva de nove ministérios e secretarias especiais da Presidência da República, além da SPM e do CNDM, representando a sociedade civil, no cumprimento de suas metas.

9 As informações que constam da "ficha perfil" se referem a dados de pessoal, formas de recrutamento e seleção, processos de capacitação e treinamento, ascensão funcional e plano de carreira, programas de saúde e segurança no trabalho, incluindo dados sobre absenteísmo,
} 
o monitoramento da evolução do cumprimento do plano de ação pelo Comitê Pró-Equidade de Gênero. ${ }^{10}$

As primeiras ações de monitoramento previstas na metodologia são a avaliação do preenchimento da ficha-perfil e a "pactuação" do plano de ação entre a empresa e a SPM. Essa "pactuação" consiste basicamente em uma avaliação da viabilidade do plano elaborado pela empresa e de sua coerência em relação aos problemas e desafios apontados pela ficha-perfil. Após um período determinado, a edição do programa é encerrada com a concessão do selo Pró-Equidade de Gênero àquelas empresas que cumpriram, ao longo do ciclo, os propósitos estabelecidos no plano de ação.

Serão analisadas a seguir as principais características e resultados da primeira edição do programa (setembro de 2005 a dezembro de 2006). ${ }^{11}$ A primeira observação a ser feita é que, evidentemente, o prazo de pouco mais de um ano decorrido entre o início e o final dessa primeira edição é insuficiente para promover uma transformação mais profunda nas relações de gênero no interior de qualquer empresa ou organização. Nesse sentido, os resultados do programa devem ser analisados, em grande medida, a partir da sua capacidade de iniciar processos e construir espaços e canais institucionais que permitam a continuidade, aprofundamento e consolidação do próprio Programa e, evidentemente, das mudanças iniciadas durante a sua implementação. Um indicador importante é o fato de todas as empresas que receberam o selo na $1^{\mathrm{a}}$ edição do Programa aderiram à sua $2^{\mathrm{a}}$ edição, evidenciando sua disposição de dar continuidade ao processo.

política de benefícios, mecanismos de combate às práticas de discriminação e à relação com terceirizadas. Para mais detalhes ver Brasil-SPM (2006b) e Abramo (2007).

${ }^{10}$ O Comitê Pró-Equidade de Gênero é responsável pelas deliberações referentes ao programa. Foi criado pela Portaria n ${ }^{\circ} 40$ da SPM (22 de setembro de 2005), e está composto pela SPM (que tem a função de coordenação), o Ministério do Planejamento, Orçamento e Gestão, Ministério do Trabalho e Emprego, Ministério Público do Trabalho, Unifem, OIT, e duas especialistas com reconhecida competência técnica em questões relacionadas à equidade de gênero no mundo do trabalho.

11 A segunda edição do programa ainda está em curso. 
A segunda observação se refere à importante participação das empresas do setor eletroenergético, que respondem por 11 das 16 empresas que assinaram o Termo de Adesão e 10 das 11 que foram premiadas na sua $1^{\mathrm{a}}$ edição. $^{12}$

Há várias razões que parecem explicar esse fato. Em primeiro lugar, o compromisso da alta direção do Ministério de Minas e Energia (MME), ao qual estão vinculadas essas empresas, na pessoa da então ministra da pasta, Dilma Roussef. Em julho de 2004 foi criado, por portaria ministerial, o Comitê Permanente de Gênero do MME, com representação das empresas vinculadas ao Ministério, após uma significativa participação de suas funcionárias e de representantes das empresas do setor na I Conferência Nacional de Políticas para as Mulheres. O objetivo do Comitê era iniciar a implementação das ações propostas pelas políticas públicas do governo federal, em sintonia com as diretrizes do MME e do PNPM. A partir desse momento, o comitê passou a estimular a criação de estruturas semelhantes em cada uma das empresas vinculadas, reforçando assim o trabalho já existente em algumas delas. Esses antecedentes favoreceram a adesão dessas empresas ao Pró-Equidade.

Em segundo lugar, o contexto de implantação do novo modelo do setor elétrico, no qual as empresas deixam de ter monopólio sobre uma determinada área geográfica e passam a receber uma série de pressões no sentido de aumentar a sua eficiência e competitividade, assim como a responder a critérios de qualidade e de responsabilidade social. Nesse contexto, a questão da igualdade de gênero adquire importância.

Trata-se de empresas que trabalham com uma visão de busca de excelência, de uma gestão de processo que inclui indicadores de desempenho e de resultados,

\footnotetext{
12 As empresas do setor elétrico-energético que assinaram o Termo de Adesão ao programa foram: Eletronorte, Cepel, CPRM, CGTEE, Ceal, Eletrobrás, Eletronuclear, Eletrosul, Furnas, Itaipu Binacional, Petrobrás. Dessas, apenas a CPRM não apresentou Plano de Ação. As outras 5 eram: Banco do Brasil, Caixa Econômica Federal, Banco do Nordeste, Radiobrás e Embrapa. Destas últimas, apenas a CEF obteve o Selo (Brasil-SPM, 2006b).
} 
e que procuram obter as certificações ISO (ISO 9 000, ISO 14 000). Isso é uma exigência do cliente. E os próprios critérios dessas certificaçôes vão exigindo que as empresas respondam a esses temas. Além disso, a própria agência fiscalizadora (a Aneel) estabeleceu como obrigação, a partir de 2003, que as empresas do setor elétrico incluissem esses indicadores nos seus relatórios sociais. E o que incomodou internamente foi quando a empresa se deparou com a ausência total de indicadores de gênero, porque ela não tinha o que responder, principalmente aos critérios de credenciamento das empresas para os investimentos internacionais. A empresa percebeu que aí havia uma lacuna muito grande, e que precisava encontrar uma forma de preencher essa lacuna. (entrevistada - membro do comitê de gênero de uma das empresas participantes do Programa).

Em muitas das empresas do setor já existia um trabalho anterior relacionado aos temas de gênero. ${ }^{13}$ Com o Comitê Permanente de Gênero no MME cria-se um espaço institucional e um mandato importante para o aprofundamento desse trabalho. Por sua vez, o surgimento do Pró-Equidade foi visto como uma nova oportunidade, que se somava a outras atividades que vinham sendo desenvolvidas por outros órgãos de governo e instituições, ${ }^{14}$ e como o mecanismo que permitia concretizar os objetivos que estiveram na origem da criação do Comitê de Gênero do MME:

Entre a criação do comitê e a instalação do programa, o processo foi muito lento. E quando o programa surge, surge o mecanismo. Isso foi muito bem percebido pela direção da empresa (...). A empresa precisava ter um instrumento. E como o Pró-Equidade é um instrumento governamental, legalizado, respaldado, foi fácil para a empresa superar os obstáculos que muitas vezes existem, aquela discussão burocrática de "isso pode", "isso não pode.' O programa potencializou e deu uma outra dimensão a um trabalho que já vinha sendo desenvolvido. A atuação do Comitê [da empresa] hoje é toda pautada pelas diretrizes do Pró-Equidade. (idem)

\footnotetext{
$\overline{13}$ Ver análise a respeito em Abramo (2007, p. 313).

${ }^{14}$ A entrevistada aqui faz referência ao programa Brasil, Gênero e Raça do MTE, à atuação dos Núcleos de Combate à Discriminação das Delegacias Regionais do Trabalho e ao programa de Fortalecimento Institucional para a Igualdade de Gênero e Raça, Erradicação da Pobreza e Geração do Emprego (GRPE), que vinha sendo desenvolvido em parceria com a OIT desde 2003, evidenciando, portanto, a existência de um processo que passa a ser reforçado pelo PróEquidade.
} 
É necessário sublinhar também que, durante a vigência do Pró-EqUidade, foram criados espaços de interlocução entre as empresas do setor eletro-energético para além das instâncias do programa, o que possibilitou a troca de experiências e o reforço mútuo em relação a alguns aspectos comuns dos planos de ação. Um exemplo disso foi a orientação do Comitê Permanente para as Questões de Gênero do MME para que as empresas do setor desenvolvessem ações voltadas à transversalização da dimensão de gênero no programa Luz para Todos. ${ }^{15}$ Como será analisado mais detalhadamente a seguir, houve uma série de outros avanços importantes no sentido de aumentar a sensibilização dos funcionários e da direção das empresas para os temas de gênero, assim como em relação à institucionalizalção de estruturas, processos e mecanismos que abrem a possibilidade de um aprofundamento e maior permanência das ações iniciadas durante a $1^{\mathrm{a}}$ edição do programa.

A fala de outra entrevistada resume alguns desses avanços e algumas características da participação especial das empresas do setor elétrico-energético no programa Pró-Equidade:

A situação das empresas do setor elétrico-energético era diferenciada. Quando o Comitê de Gênero do MME foi criado, havia, por exemplo, uma Itaipu Binacional com um histórico de preocupação com a questão de gênero. Mas, por outro lado, havia empresas onde os macacões eram feitos todos do mesmo tamanho, para homens; plataformas da Petrobrás que não tinham banheiro para as mulheres. Nas empresas de energia elétrica, o Comitê de Gênero está respaldado por uma determinação da Ministra da época, formado e institucionalizado. Eles têm mandato, têm poder e, junto com isso, eles estão inseridos num Plano Nacional de Política para as Mulheres - são responsáveis por uma das ações do Plano, e têm que prestar contas disso. E, ao mesmo tempo, as empresas que aderem ao Pró-Equidade colocam os seus planos de ação para o Programa como parte de seus planejamentos estratégicos. Em algumas empresas do setor há ações do Pró-Equidade definidas até 2010. E são essas empresas as responsáveis pelo Luz.para

15 É interessante notar que, no caso das três empresas do setor bancário que aderiram ao programa, não ocorreu esse tipo de articulação. 
Todos. No site de todas elas há uma página falando do Pró-Equidade e da igualdade de gênero. Tudo isso representa um avanço muito considerável. (entrevistada - gestora da SPM).

\section{Tornando mais visíveis as desigualdades de gênero e raça}

O primeiro resultado digno de nota do Programa foi tornar mais visível a existência de desigualdades entre homens e mulheres em termos de ingresso, ascensão e promoção, salários e remunerações, acesso aos postos de comando e decisão no interior das empresas. Esse resultado deriva inicialmente do preenchimento da "ficha perfil" e do autodiagnóstico feito a partir daí - primeira ação realizada após a adesão das empresas ao programa e que precede a definição do Plano de Ação. E, em muitos casos, se aprofunda em outras ações. ${ }^{16}$

É interessante observar que o diagnóstico das desigualdades de gênero frequentemente está acompanhado pela consideração da questão racial. Certamente a solicitação de desagregação dos dados da ficha perfil não apenas por sexo mas também por cor/ raça estimula essa consideração. Isso é reflexo, também, de uma tendência a articular os temas de gênero e raça que já estava presente em alguns setores do movimento social de mulheres e negros no Brasil e que ganha força com a criação da Seppir e da SPM e com a orientação dada pelas duas ministras (Matilde Ribeiro e Nilcea Freire) no sentido de entender as desigualdades de gênero e raça como duas dimensões fundamentais e articuladas da desigualdade social no País, assim como com a inclusão de ambos os temas,

\footnotetext{
${ }_{16}$ Conforme a metodologia definida pelo Comitê de Monitoramento, os Planos de Ação se estruturam em dois eixos: "gestão de pessoas" e "cultura organizacional". O primeiro se divide em cinco blocos: a) recrutamento e seleção; b) capacitação e treinamento; c) ascensão funcional e planos de carreira, cargos, salários e remuneração; d) saúde e segurança no trabalho; e) política de benefícios. O segundo estrutura-se em três blocos: a) combate às práticas de discriminação e ao assédio moral e sexual; b) políticas de sensibilização na cadeia de relacionamentos da empresa; c) propaganda institucional interna e externa.
} 
com essa mesma perspectiva, no PPA 2004-2007, vinculados ao primeiro megaobjetivo do Plano, referido ao crescimento do produto e do emprego e ao combate às desigualdades sociais.

\section{Ações no campo do recrutamento e seleção de pessoal}

A ação mais freqüentemente realizada pelas empresas em relação ao recrutamento e seleção de pessoal foi a inclusão dos quesitos sexo e cor no cadastro das empresas e a realização de diagnósticos e análises sobre esse tema com dimensão de gênero e raça. Apesar de não ter uma interferência imediata na política de contratação das empresas, esse tipo de ação é relevante, já que conhecer a estrutura ocupacional de cargos e salários em termos da sua composição por sexo e raça/cor é, evidentemente, uma condição básica para tornar visíveis as desigualdades existentes, assim como para a formular e monitorar ações de promoção da igualdade. A inclusão dos quesitos sexo, ou sexo e cor, nos cadastros dos funcionários e/ou nos sistema de informação das empresas implicou, em muitos casos, vencer resistências importantes e desenvolver estratégias de aproximação, convencimento e capacitação de vários setores das empresas. Entre eles, os departamentos de informática e os profissionais envolvidos no desenho dos sistemas e na coleta e análise dos dados. Isso, muitas vezes, implicou também em custos (referentes, por exemplo, a novos softwares e sistemas, gastos de capacitação, redefinição de procedimentos), o que supunha a concordância das autoridades da empresa. Foram também realizadas, em algumas empresas, pesquisas ou diagnósticos desagregados por sexo (e raça) sobre a estrutura ocupacional e de cargos e salários. ${ }^{17}$

Em alguns casos, as ações foram além do registro e do diagnóstico, e envolveram a introdução de algum tipo de mudança

17 Para mais detalhes ver Brasil-SPM (2006b) e Abramo (2007). 
nas práticas de recrutamento e seleção da mão-de- obra. Em Furnas, por exemplo, os textos das normas das empresas e os editais de concursos foram alterados no que se refere à nomenclatura dos cargos, com o objetivo de respeitar a diversidade e garantir a igualdade de oportunidades entre mulheres e homens, citando denominações profissionais no feminino e no masculino (BrasilSPM, 2008). Apesar de poder parecer uma mudança menor, esse tipo de medida é importante para o combate aos estereótipos de gênero. $\mathrm{Na}$ Eletronorte foram estabelecidos procedimentos normativos nos processos de contratação de mão-de-obra terceirizada permanente e estagiários, contemplando a inclusão de negros, indígenas, mulheres e portadores de necessidades especiais. $\mathrm{Na}$ Itaipu Binacional, como resultado da pesquisa realizada de atualização do perfil social, o Fórum de Gênero apresentou ao superintendente de Recursos Humanos as seguintes reivindicações: revisão do plano de cargos para empregados e empregadas, com equiparação salarial para aqueles/as que exercem a mesma função; aumento das oportunidades para que as mulheres possam ascender a cargos de chefia e de direção; incentivo ao estudo da situação dos funcionários do sexo masculino incluindo a perspectiva de gênero; participação das mulheres em todas as decisões que dizem respeito à carreira, salários e assuntos gerais da empresa; implantação de uma ouvidoria para as questões da mulher; considerar os cursos de capacitação em gênero como passíveis de pontuação para efeito de promoção interna.

\section{Processos de capacitação e treinamento interno}

Essa foi a área que concentrou o maior número de ações da primeira edição do Pró-Equidade. Foi realizado um número significativo de palestras, conferências, seminários, oficinas e ações educacionais e atividades de sensibilização que incluíam a própria divulgação da existência do programa. Em várias empresas houve uma preocupação especial com a capacitação de gestores/as e do Comitê Permanente de Gênero. Na Ceal (Companhia Energética 
de Alagoas) o recorte de gênero foi incorporado nos cursos e treinamentos e a desagregação dos dados por escolaridade, sexo e cor/etnia foi introduzida no Banco de Dados de Treinamentos. ${ }^{18}$ Essas parecem ser medidas importantes para ampliar o trabalho de sensibilização e qualificação dos funcionários da empresa no tema de gênero. Mas é necessário acompanhar o desenvolvimento desses processos e avaliar em que medida essa sensibilização tem contribuído tanto para a transformação das relações internas da empresa no sentido de uma maior igualdade de gênero, quanto para a introdução de algum tipo de perspectiva de gênero nas suas políticas e estratégias externas, ou seja, em relação aos seus serviços e produtos. Considerando que se trata de empresas públicas e de economia mista, é importante ver até que ponto a perspectiva de gênero vem sendo incoporada na política eletro-energética do País e em que medida o ProEquidade vem contribuindo (ou pode contribuir) a isso. ${ }^{19}$

Por outro lado, em quase todas as empresas que aderiram ao Pró-Equidade, o tema da igualdade de gênero foi incorporado na propaganda institucional. Passou-se a prestar atenção às imagens veiculadas com o objetivo de evitar a reprodução de estereótipos de gênero e estimular a promoção consciente e explícita da diversidade.

\section{Ascensão funcional e planos de carreira, cargos, salários e remuneração}

Segundo o relatório da SPM publicado em 2006, as ações realizadas neste bloco tiveram um caráter preparatório para o que

\footnotetext{
${ }_{18} \mathrm{Na}$ Petrobrás foram garantidos, no Plano Estratégico da empresa, recursos específicos para treinamento na área de gênero/diversidade, e está prevista a ampliação do currículo dos cursos oferecidos pela Universidade Petrobrás para incluir e aprofundar o tema Gênero e Diversidade. Em outra empresa foram ampliadas as ofertas de treinamento nas áreas administrativa e financeira, onde se concentram as mulheres, e em outra ainda estava prevista a promoção de cursos de especialização para mulheres (com carga horária de 456 horas), capacitando-as para posições gerenciais.

${ }^{19}$ Como uma contribuição para essa discussão, ver análise sobre a possível contribuição do Luz para Todos para a promoção da igualdade de gênero no país em Abramo (2007, capítulos 7 e 8).
} 
poderia vir a constituir mudanças mais significativas nos processos de definição das remunerações, planos de cargos e ascensão funcional. Como se verá a seguir, com algumas exceções, a maioria das ações consistiu basicamente na realização de diagnósticos, mas, em alguns casos, foram implementadas algumas mudanças concretas, entre as quais se destacam:

a) definição de uma meta de aumento da presença de mulheres e negros em cargos de chefia e gerenciais $(10 \%)$, como uma tentativa de responder ao problema identificado na ficha perfil, de baixíssima representação de mulheres nos cargos diretivos da empresa - para acompanhar o cumprimento dessa meta, foram elaborados indicadores de gênero e raça na ocupação de cargos, divulgados mensalmente, e instituído o reconhecimento das Regionais com o melhor indicador de gênero, o que estimula o aumento da presença de mulheres nesses cargos (Caixa Econômica Federal) (Brasil-SPM, 2008);

b) definição e divulgação de indicadores de gênero e raça na ocupação de cargos comissionados e acompanhamento e divulgação da informação relativa à evolução do número de mulheres ocupantes de cargos comissionados;

c) criação de uma comissão para avaliação do plano de cargos e salários, a fim de se obter uma maior clareza em relação aos critérios de avaliação de desempenho e de resultados, com contratação de consultoria externa para analisar a relação entre as ocupações, o tempo de serviço e o salário-base, com dados desagregados por sexo;

d) proposta de implantação do projeto sobre "Bolsa de Transferência”, com a finalidade de possibilitar processos de permuta dos/as empregados/as e dar maior visibilidade aos processos de recrutamento, seleção 
e transferência dos postos de trabalho - a suposição aqui é que a transparência do processo favorece as mulheres. ${ }^{20}$

Para avaliar o possível impacto dessas medidas na promoção da igualdade de gênero seria importante verificar se elas foram mantidas, ampliadas e/ou aprofundadas na segunda edição do Programa.

\section{A incipiência dos programas de saúde e segurança no trabalho com perspectiva de gênero}

As iniciativas mais freqüentes desenvolvidas nessa área foram: estímulo a ações de saúde preventiva e de atenção integral à saúde da mulher (em alguns casos estendendo esse benefício também às trabalhadoras terceirizadas); exame preventivo de câncer de mama e de órgãos reprodutivos femininos para empregadas acima de 40 anos; campanha sobre tensão pré-menstrual e menopausa e sobre a saúde da mulher negra e realização e publicação de estudos sobre a influência negativa do assédio moral sobre o desempenho das mulheres no trabalho.

Uma iniciativa que se destaca pela sua importância é a decisão de uma das empresas de proceder ao registro e análise do absenteísmo (incluindo as suas causas mais frequentes) com dados desagregados por sexo e cor/etnia. Estudos anteriores (Castillo, 1994, Abramo; Todaro, 2002, Abramo, 2007) evidenciaram a importância de contar com esse tipo de dados - em geral não disponíveis - não apenas para enfrentar alguns problemas importantes das relações de trabalho e da gestão de recursos humanos, como também para o questionamento de certos mitos associados às mulheres no trabalho e que contribuem para conformar a sua imagem como força de trabalho secundária.

\footnotetext{
${ }^{20}$ A opinião do Comitê de Monitoramento do Pró-Equidade é que essa inovação permitiria avançar na adequação entre o perfil e as funções desempenhadas por homens e mulheres.
} 
Também é interessante a iniciativa de outra empresa incorporar ao protocolo de intenções assinado entre a empresa e o sindicato no âmbito do acordo coletivo de trabalho 2006-2007 um estudo para viabilizar a ampliação dos exames periódicos (câncer de próstata, mama e útero). Em outras duas empresas foram desenvolvidas ações dirigidas a incorporar a dimensão de gênero nos diagnósticos e programas relativos à qualidade de vida no trabalho. Em outra, por iniciativa da área de saúde e segurança do trabalho, foi elaborado um questionário incluindo a questão de gênero, com perguntas sobre efeitos da discriminação no ambiente de trabalho.

No entanto, é necessário chamar a atenção para a quase total ausência de ações e programas mais diretamente relacionados aos temas de saúde e segurança ocupacional, tais como a elaboração de mapas de risco ou análises das doenças e enfermidades ocupacionais levando em conta as dimensões de gênero e raça. Vale notar que esse também é um tema pouco frequente nos processos de negociação coletiva, tal como analisado pelo Departamento Intersindical de Estatística e Estudos Socioeconômicos (Dieese, - 2003) e por Abramo e Rangel (2005).

\section{Política de benefícios: ausência de ações para a ampliação da proteção à mater-paternidade e de conciliação entre trabalho e família}

Chama a atenção aqui o baixíssimo desenvolvimento de ações relativas à extensão dos direitos de mater-paternidade e à reconciliação entre a vida e o trabalho. Pode-se dizer que esses temas estão totalmente ausentes dos Planos de Ação das empresas, com três únicas exceções, que, além do mais, são de alcance bastante limitado, quando não duvidoso. As primeira delas é a inclusão, no plano de ação de uma das empresas, de uma ação destinada a garantir o tempo e o espaço apropriados para a amamentação. A segunda é a adoção, por outra empresa, das seguintes medidas: 
dispensa da empregada mulher para acompanhar o filho menor em casos de exames médicos ou internamentos, sem prejuízo da remuneração e mediante a apresentação de atestado médico; dispensa da mãe e do pai para acompanhar filho/a menor nas festividades alusivas aos dias das mães e dos pais, sem prejuízo do salário e garantia de licença maternidade em caso de adoção de filho/a. A terceira é a adoção de uma licença sem remuneração de até dois anos após a licença maternidade que está em estudo em outra empresa - discute-se com o Sindicato a inclusão dessa possibilidade no acordo coletivo. ${ }^{21}$

É necessário assinalar que a garantia de uma hora diária para a amamentação já está prevista na CLT até que a criança tenha seis meses, assim como o gozo da licença maternidade no caso da adoção de filhos. ${ }^{22}$ Por sua vez, em relação à licença não remunerada por um período de até dois anos após o final da licença-maternidade, poderíamos tecer as seguintes considerações: a existência dessa possibilidade pode ser considerada positiva no sentido de ser uma alternativa a mais para as mulheres que desejem e possam ausentar-se do trabalho sem remuneração durante os dois primeiros anos de vida dos filhos/as, tendo a garantia de uma volta ao emprego após o término desse período. Esse benefício equivale ao que na Argentina é chamado de "estado de excedência” que, na prática, é de difícil aplicação (Berger; Szretter, 2002). Em primeiro lugar porque não são muitas as mulheres que podem prescindir do seu salário durante dois anos. Em segundo lugar porque esse período prolongado de ausência ao trabalho pode ter consequências negativas também em termos das suas possibilidades de promoção na empresa, avaliação do desempenho, etc. Há com efeito uma forte discussão a esse respeito nos países da União Européia. ${ }^{23}$

\footnotetext{
${ }^{21}$ As outras ações registradas nesse item são as seguintes: revisão dos benefícios existentes para identificar condições diferenciadas necessárias à promoção da igualdade de gênero; equipar os banheiros femininos com armários funcionais; realização de estudo para analisar a viabilidade de concessão de bolsa educacional; inclusão de companheiros/as do mesmo sexo nos planos de saúde da empresa.

22120 dias no caso da adoção de criança até um ano de idade, 60 dias entre 1 e 4 anos e 30 dias entre 4 e 8 anos.

23 Ver discussão a respeito em Abramo (2007, capítulo 6).
} 
A ausência de propostas mais consistentes de ampliação dos direitos de mater-paternidade e de conciliação entre o trabalho e a vida familiar pode ser considerada, assim, uma limitação importante dessa primeira edição do Pró-Equidade. A existência de políticas e programas (tanto no âmbito das políticas públicas, quanto das políticas de recursos humanos das empresas) que favoreçam a diminuição da tensão entre a vida familiar e o trabalho, tanto para homens quanto para as mulheres, é um aspecto fundamental de uma política de promoção da igualdade de gênero.

Chama a atenção, portanto, a ausência desse tema nessa primeira edição do Pró-Equidade, assim como a sua debilidade no PNPM, ${ }^{24}$ tanto mais se consideramos dois fatores. O primeiro deles é o fato de que as empresas em questão são empresas formais, organizadas, modernas e com uma quantidade importante de benefícios para o corpo de funcionários, em geral, ou seja, empresas que teriam condições, muito mais que a média das empresas brasileiras, de desenvolver esse tipo de políticas. Em segundo lugar o fato de que este tema está presente de maneira relativamente expressiva nos processos de negociação coletiva desenvolvidos no país. Ainda que com uma freqüência baixa se comparada, por exemplo, aos países da União Européia ou ao Canadá, tem havido avanços importantes nesse âmbito, tanto no sentido da garantia dos direitos legais existentes quanto da sua ampliação: extensão das licenças maternidade e paternidade, melhoria da qualidade e extensão do período legal em que as empresas estão obrigadas a fornecer a creche ou o auxílio-creche, extensão do direito à creche para os pais, extensão do período de estabilidade no emprego após o término da licença-maternidade, estabilidade para os pais no caso de nascimento de filho/a etc. ${ }^{25}$

\footnotetext{
${ }^{24}$ No I PNPM foram incorporados apenas dois temas relativos à conciliação trabalho-família: a meta de aumentar em $12 \%$, entre 2004 e 2007, o número de crianças entre 0 a 6 anos frequentando creche e pré-escola e as ações de apoio a Estados e municípios na construção de equipamentos sociais para facilitar a inserção e permanência das mulheres no mercado de trabalho (creches, restaurantes e lavanderias públicas).

${ }^{25}$ Ver análise mais detalhada a respeito em Dieese (2003), Gebrim (2005), Abramo e Rangel (2005) e Abramo (2007).
} 


\section{Combate às práticas de discriminação e ao assédio moral e sexual}

A maioria das ações desenvolvidas em relação a esse tema é de capacitação e/ou sensibilização, além da constituição de comitês, grupos ou fóruns ("estruturas de gênero") que tomam a si a responsabilidade pela implementação do Programa. Como ações mais estruturantes (e menos frequentes), destacam-se a criação de códigos de conduta, ${ }^{26}$ ouvidorias, ${ }^{27} \mathrm{O}$ estímulo à incorporação de cláusulas de promoção da igualdade de gênero e raça-etnia nas convenções coletivas de trabalho e a inserção da política de gênero no planejamento estratégico das empresas (Brasil-SPM, 2006b, p. 46).

Foi realizado um número significativo de ações de sensibilização e capacitação dos funcionários e funcionárias das empresas (incluindo os membros dos Comitês de Gênero, gerências, chefias de departamento e níveis variados de hierarquia) nos temas da igualdade de gênero. Além dos princípios gerais da igualdade e da não discriminação, de dados e análises sobre a situação da mulher e as relações de gênero no mercado de trabalho, foram realizadas, em algumas empresas, campanhas de prevenção do assédio sexual e moral, pelo fim da violência contra a mulher ${ }^{28}$ e promoção de ações de impacto em datas alusivas como, por exemplo, o 25 de novembro (Dia Internacional de Combate à Violência contra a Mulher) e 10 de dezembro (Dia da Declaração Universal de Direitos Humanos).

\footnotetext{
${ }^{26}$ Em três empresas do setor eletroenergético foram elaborados ou reelaborados códigos de ética e de conduta profissional com o objetivo de incluir a dimensão de gênero. A nova versão do Código de Ética e do Plano Estratégico da Petrobrás, por exemplo, inclui referências ao "respeito à diversidade" e à não discriminação de etnia, raça, sexo, orientação sexual, idade e deficiência (SPM, 2006b, p. 28).

$27 \mathrm{Na}$ Ouvidoria-Geral da Eletrobrás foi criado um canal específico de atendimento aos temas de gênero. Na Petrobrás, a Ouvidoria Geral e a Comissão de Gênero são parte integrante do Comitê Gestor de Responsabilidade Social e Ambiental. Na CEF, a questão de gênero está incluída no Sistema Informatizado de Ouvidoria Interna, que possibilita o registro de reclamações, sugestões e elogios.

${ }^{28}$ Várias empresas passaram a aderir à Campanha de " 16 dias de ativismo pelo fim da violência contra a mulher" promovida todos os anos, no mês de novembro, pelo governo e várias instituições da sociedade.
} 
Em várias empresas foram criados comitês ou fóruns permanentes para as questões de gênero e foram desenvolvidos esforços para que haja participação masculina e representação de várias áreas das empresas nesses comitês.

Além disso, foram tomadas outras iniciativas, entre as quais a de diagnosticar a cultura organizacional das empresas, com o objetivo de incorporar o "recorte de gênero" e verificar a existência ou não de práticas discriminatórias.

\section{Políticas de sensibilização voltadas para a eqüidade de gênero na cadeia de relacionamentos da empresa}

Outro aspecto importante do trabalho realizado foi a tentativa de desenvolver ações na chamada cadeia de relacionamentos da empresa, ou seja, nas cadeias produtivas nas quais as empresas que aderiram ao Programa estão inseridas. Entre essas ações, se destacam:

a) realização de campanhas para prevenção do assédio sexual e moral;

b) desenvolvimento de pesquisa sobre o perfil da trabalhadora terceirizada;

c) definição de indicadores e critérios para avaliação dos Projetos Sociais desenvolvidos pela empresa e para a realização de contratos com seus prestadores de serviços e fornecedores, incluindo o respeito à diversidade de gênero;

d) inclusão nos editais e contratos de cláusula determinando ao contratante a observância ao Código de Ética e ao Código de Conduta Profissional dos Empregados (com perspectiva de gênero) e dando ciência do assunto às empresas já contratadas e seus empregados;

e) manutenção do salário das mulheres grávidas terceirizadas até o final da licença-maternidade em caso de ruptura dos seus contratos; 
e) realização de palestras com gerentes das empresas contratadas e terceirizadas sobre a importância da equidade de gênero;

f) atuação junto às empresas federais de distribuição de energia que fazem parte da "cadeia de relacionamento" recomendando diretrizes e estratégias para promover e fortalecer as ações afirmativas de gênero.

\section{Propaganda institucional interna e externa}

As empresas em geral realizaram um esforço para incluir na propaganda institucional da empresa o tema de gênero, a existência do Pró-Equidade e as ações realizadas no contexto do Programa. Por diversos meios foram divulgadas a criação e as atribuições do Programa e do Comitê Permanente de Gênero do MME, assim como dos comitês de gênero das empresas. Foram também criadas logomarcas e/ou slogans simbolizando o esforço empresarial para a internalização da abordagem de gênero na gestão empresarial, com o objetivo de divulgar mensagens favoráveis à construção da igualdade entre homens e mulheres; foram criados espaços específicos dedicados ao programa nos sites das empresas, assim como no seu material impresso. Em algumas empresas também foi desenvolvido um trabalho de análise dos materiais de propaganda institucional com o objetivo de identificar e eliminar possíveis conteúdos discriminatórios.

\section{Ações "transbordantes"}

Foram denominadas de "ações transbordantes" as iniciativas que "transbordam" os limites da empresa, seus funcionários e funcionárias e suas estruturas e que não estavam inicialmente previstas. São elas basicamente algumas iniciativas de responsabilidade social ou voltadas à incorporação de componentes de promoção da igualdade de gênero nas políticas 
sociais desenvolvidas no âmbito de atuação das empresas, como, por exemplo, o Programa Luz para Todos no caso das empresas do setor eletro-energético.

As informações disponíveis não são suficientes para dar uma idéia mais clara da medida em que as ações realizadas pelas empresas no contexto do Pró-Equidade contribuíram, efetivamente, para a inclusão da perspectiva de gênero nas suas ações de responsabilidade social. Registram-se algumas iniciativas de desenvolvimento de projetos sociais com foco na capacitação, geração de renda e autonomia das mulheres e apoio a prefeituras ou organizações da sociedade civil dedicadas à luta pelo fim da violência contra as mulheres.

No entanto, um depoimento dado por uma das gestoras entrevistadas no decorrer da pesquisa dá indicações de mudanças que poderiam estar ocorrendo nesse âmbito, não apenas como resultado do Pró-Equidade, como também do processo de adoção do "novo modelo do setor elétrico" já discutido anteriormente neste artigo.

Antes da adesão da empresa ao Pró-Equidade, ela fazia políticas compensatórias e dizia que fazia responsabilidade social, e que estava dando uma resposta aos impactos ambientais. Mas, na verdade, as ações eram puramente compensatórias. Por exemplo, no processo de construção de uma usina, uma área era alagada e a comunidade que vivia nessa área era remanejada para uma outra terra da União. E se na área alagada havia uma escola, ela construía uma escola na nova área; se havia um comércio, ela indenizava o comércio; se havia pequenas plantações, geralmente ribeirinhas, ou de várzea, elas também eram indenizadas. E ai pronto. A empresa indenizava e não se preocupava mais em saber se a população conseguia reproduzir o seu modo de subsistência na nova área em que era relocalizada. A população era tirada totalmente do seu habitat natural, que é margem de rio. E aí, o que acontecia? Acabava o dinheiro e a população voltava para o habitat anterior, e ai vinha numa condição de pobreza, de exclusão, por que ficava sem escola, sem a plantação, sem nada.

E ai a empresa considerava que tinha cumprido totalmente a lei de compensação. E cumprida essa lei, não tem mais obrigatoriedade nenhuma, 
não tem mais nenhuma lei que obrigue a empresa a fazer mais nada. Agora - e isso não é um efeito apenas do Pró-Equidade, mas também de toda a discussão do novo modelo do setor elétrico - a empresa começa a pensar que onde for instalada uma usina, uma subestação, uma linha de transmissão, é necessário, além de fazer todo o estudo dos impactos ambientais, desenvolver políticas que não são mais apenas compensatórias, mas sim auto-sustentáveis.

A contradição que havia era muito grande: o empreendimento era feito para gerar energia. A comunidade remanejada não tinha energia. Era remanejada justamente para que a energia fosse gerada. Ai passavam os cabos em cima daquela população remanejada, levando energia por todo o Sudeste. E ela continuava sem ter energia. Agora, em qualquerprojeto que se faça, a primeira condição definida é que a comunidade local tenha acesso à energia. A segunda é que se desenvolvam politicas sustentáveis através de uma integração de políticas públicas de governo. Não basta construir a escola. A prefeitura tem que garantir o orçamento para a escola funcionar. Nós construimos muitas escolas, mas muitas delas não estão funcionando porque a prefeitura não destinou recursos para pagar professores, para colocar os móveis na escola. Tudo isso começa a mudar a posição da empresa em relação ao tema da responsabilidade sócio-ambiental. (entrevistada - gestora da SPM)

Tal como já foi assinalado, seria importante acompanhar o desdobramento do Programa para verificar a sua potencialidade em transformar esse tipo de ações mais isoladas, definidas como "transbordantes", em um trabalho mais sistemático voltado para a incorporação da perspectiva de gênero nos produtos e serviços oferecidos pelas empresas, que, no caso das empresas do setor eletro-energético, constituem políticas de infra-estrutura fundamentais para o desenvolvimento do País e que não são neutras em termos de gênero.

\section{Avanços, dificuldades e fatores de sucesso}

Como já foi assinalado, o pouco tempo de existência do Programa Pró-Equidade de Gênero não permite uma análise mais conclusiva sobre os seus resultados e potencialidades. O 
seu principal mérito, até agora, talvez tenha sido o de constituir uma iniciativa estruturada de estímulo à promoção da igualdade de oportunidades de gênero (articulada à questão racial) em um conjunto de grandes empresas estatais, com grande visibilidade pública no Brasil, a maioria delas localizadas em um setor tradicionalmente muito masculinizado e estratégico em termos da infraestrutura de desenvolvimento do Brasil.

Entendemos por "iniciativa estruturada" o fato de o programa apresentar-se às empresas como parte de um conjunto articulado de ações e iniciativas que se expressa no I e no II Plano Nacional de Políticas para as Mulheres que, por sua vez, foram construídos a partir de importantes processos participativos expressos na realização da I e da II Conferências Nacionais de Políticas para as Mulheres (2004 e 2007), e que contam com mecanismos de monitoramento e avaliação periódica. Isso, além do envolvimento direto da SPM e da própria ministra na divulgação e articulação do Programa, foi um fator de grande importância para a sua instalação em um lugar de destaque nas empresas. $\mathrm{O}$ fato de todas as empresas que receberam o selo na primeira edição do Programa terem aderido à sua nova edição, assim como o fato de que esta tenha sido aberta às empresas privadas, é também uma indicação de que há um grande potencial para o desenvolvimento e consolidação desse tipo de iniciativa. Essa nova situação, ao mesmo tempo em que abre a possibilidade de ampliação da escala e do impacto do programa, coloca novos desafios no que diz respeito ao seu monitoramento.

Entre as principais dificuldades para a execução do Programa na primeira edição (e que foram apontadas nos relatórios de monitoramento) estava, em primeiro lugar, o fato de tratar-se de empresas (a maioria delas criada durante o regime militar) com estruturas internas fortemente hierarquizadas, com uma composição da força de trabalho eminentemente masculina e com uma "cultura empresarial" que correspondia a essas duas características. Em segundo lugar, a segmentação interna da sua 
força de trabalho, caracterizada pela existência de quadros de pessoal compostos por funcionários concursados, trabalhadores terceirizados e aprendizes/estagiários, com claras diferenças em termos de situação funcional, status, benefícios, direitos. Em alguns casos, a implementação dos Planos de Ação enfrentou resistência de chefias e gerências ou de alguns setores das empresas, como o de Recursos Humanos.

Entre os principais fatores de êxito do Programa destacase, em primeiro lugar, o fato de ele estar inscrito no marco mais amplo de uma política de governo (o PNPM), ter sido definido como uma atividade prioritária da SPM e ter contado com um empenho direto e especial da ministra titular da Secretaria. Em segundo lugar, o comprometimento da alta direção das empresas que aderiram ao Programa. ${ }^{29}$

O outro fator importante foi a criação de "estruturas de gênero" no interior de cada uma das empresas que aderiram ao programa (comitês permanentes para as questões de gênero, fóruns, ouvidorias) e a articulação dessas estruturas com outros departamentos das empresas, como, por exemplo, a área de recursos humanos, de responsabilidade social, informática (fundamental para a introdução dos quesitos cor e sexo nos cadastros de funcionários), comissões ligadas à definição dos planos de cargos e salários, departamentos de segurança e medicina do trabalho etc. Essas estruturas, aliadas a um grupo maior ou menor de funcionários e funcionárias (principalmente funcionárias) existente em cada uma das empresas, foi fundamental para assentar as bases de implementação do Programa. A própria criação da SPM no início do governo Lula, a Criação do Comitê Permanente das Questões de Gênero no Ministério de Minas e Energia e, particularmente, o processo de mobilização para a I Conferência Nacional de Políticas para as Mulheres foram fatores muito importantes para mobilizar e "empoderar" essa

29 Em todos os casos, a carta de adesão ao Programa foi assinada pelo presidente da empresa. 
militância. A partir das atividades de sensibilização e capacitação desenvolvidas pelo programa, essa base inicial de ativismo e militância foi ampliada, empoderada, capacitada. Nas palavras de uma das entrevistadas:

O Comitê se instala como resultado de todo um trabalho que vinha sendo feito fora da empresa. Instituir um Comitê num espaço coorporativo dentro do setor elétrico é um diferencial, porque se trata de um espaço muito masculinizado e bierarquizado.

Outro elemento que, ao mesmo tempo, pode ser caracterizado como um resultado do Programa e um fator fundamental para a sua sustentabilidade, foi o seu processo de institucionalização em várias das empresas. Por processo de institucionalização entendemos, em primeiro lugar, a criação e consolidação das "estruturas de gênero" especificamente vinculadas ao Programa, o que se deu em um número significativo de casos. Em segundo lugar, a inclusão e/ou a integração do Plano de Ação (no todo ou em parte) ou de ações e objetivos de promoção da igualdade de gênero por meio de estruturas, procedimentos e processos mais gerais e já institucionalizados das empresas, tais como resoluções e diretrizes oficiais da sua alta direção, processos de planejamento estratégico e códigos de conduta.

Nesse aspecto destacam-se as seguintes experiências: na Itaipu Binacional, o Fórum de Equidade de Gênero, criado em 2005, foi institucionalizado e estruturado organicamente em 2006, com o objetivo de implementar o Plano de Ação do Pró-Equidade. No decorrer do ano, e como resultado do trabalho realizado, o Plano de Ação se transformou em programa, denominado Programa de Incentivo à Equidade de Gênero inserido no Planejamento Estratégico da empresa, com orçamento assegurado até $2011 .^{30}$

\footnotetext{
30 O Plano está composto por quatro ações: apoio a instituições, capacitação de multiplicadores, elaboração de estudos e realização de eventos. O programa é definido como temporário e deverá ser finalizado quando for transformado em política-cultura empresarial.
} 
Em Furnas, no contexto da implementação do Plano de Ação do Pró-Equidade, foi elaborada uma Declaração Oficial de Diretrizes para as Mulheres, que foi incorporada à Política de Cidadania Empresarial e de Responsabilidade Social. Esse documento, elaborado a partir do diagnóstico das relações de gênero na empresa e lançado em março de 2006 pelo seu presidente, contém cinco diretrizes:

1) promoção dos direitos sem preconceito de origem, raça, cor, sexo, idade e qualquer outra forma de discriminação;

2) criação de mecanismos que assegurem a equidade de gênero, incorporação e valorização da mulher em todas as etapas de implantação de empreendimentos de Furnas, bem como em todos os outros postos de trabalho;

3) implantação de projetos e iniciativas que confirmem o compromisso da empresa com sua força de trabalho prioritariamente feminina, corrigindo, combatendo e reduzindo as desigualdades entre os sexos;

4) ampliação das práticas de relacionamento de Furnas incorporando a nova concepção de igualdade entre os sexos e valorização da mulher;

5) ampliação e permanência do Grupo Gênero, com representantes de todas as diretorias, como meio de acompanhar e garantir a aplicação destas diretrizes. (Furnas tem diretrizes..., 2006, p. 22-23).

$\mathrm{Na}$ Eletronorte, o Programa foi incluído no Planejamento Estratégico da Empresa em maio de 2006, como uma "iniciativa estratégica" cujo objetivo está assim definido: Assegurar que a gestão depessoas esteja alinhada com os desafios empresariais. Esse procedimento, além de institucionalizar a implementação do Plano de Ação (garantindo, inclusive recursos orçamentários para tanto), exigiu a definição de indicadores e outras medidas importantes para o acompanhamento e aperfeiçoamento das ações programadas para cada período específico. A empresa assumiu um compromisso 
de cinco anos com o programa, ao planejar ações em três fases (2005-2010).

Por sua vez na Caixa Econômica Federal (CEF), o Programa Pró-Equidade passou a ser parte integrante do Programa Diversidade Caixa, que, por sua vez, foi inserido no Planejamento Estratégico da Empresa (com orçamento assegurado), o que deve garantir a sua institucionalização e continuidade.

Os outros dois fatores considerados importantes para o êxito do programa são a existência de recursos orçamentários para o desenvolvimento das ações (em várias empresas foram contratadas consultorias para realizar a pesquisa sobre o perfil da força de trabalho, elaborar relatórios, desenvolver o Plano de Ação, etc.) e o desenvolvimento de parcerias para a implementação do programa, em especial de organizações internacionais (OIT e Unifem), ONGs feministas e do movimento de mulheres, universidades, federações estaduais da indústria, núcleos de combate à discriminação no âmbito das Superintendências Regionais do Trabalho.

Em síntese, podemos dizer que o Pró-Equidade de Gênero constitui uma iniciativa importante e inovadora de promoção da igualdade de gênero, por vários motivos. Em primeiro lugar porque é resultado de uma iniciativa governamental, parte constitutiva do I e do II Planos Nacionais de Políticas para as Mulheres que, por sua vez, são resultado de amplos processos de discussão e participação social, consubstanciados na I e II Conferências de Políticas para as Mulheres. Em segundo lugar porque isso se combina com uma ação voluntária das empresas, não apenas em termos da decisão de aderir ao programa, mas também na própria definição do plano de ação a ser executado, seus objetivos e metas. Em terceiro lugar porque está voltado para empresas estruturadas, no setor formal da economia, e, nesse sentido, se destaca da maioria das ações definidas no I e II PNPM. Em quarto lugar porque esteve concentrado, na sua primeira edição, em um 
setor estratégico em termos das políticas de desenvolvimento do País e tradicionalmente masculinizado (o setor eletro-energético). Em quinto lugar porque, em um número expressivo de casos, os planos de ação contemplavam também ações que transcendiam as empresas que aderiram ao Programa e se dirigiam às suas cadeias de relacionamento, formadas por empresas de diferentes tipos e tamanhos. Finalmente, por ter incluído, também, em muitos casos, ações relativas à promoção da igualdade racial, em articulação com a questão da igualdade de gênero. ${ }^{31}$

O tempo limitado de existência do programa não permite fazer inferências mais definitivas sobre a sua capacidade efetiva de alterar de forma significativa as relações de gênero no interior das empresas. É importante que a experiência continue a ser monitorada e analisada para que se possa chegar a alguma conclusão a esse respeito. Entretanto, há algumas indicações de que o processo iniciado na primeira edição pode ser aprofundado na segunda e nas que a ela se seguirem: o fato de o Pro-Equidade continuar a ser definido como um programa prioritário no II PNPM, o fato de todas as empresas premiadas na primeira edição terem aderido à sua segunda edição, e, também, o fato de o processo de institucionalização ter ocorrido em vários casos, tal como descrito no decorrer deste artigo.

\section{Referências}

ABRAMO, Laís. A inserção da mulher no mercado de trabalho: uma força de trabalho secundária? 2007. 360f. Tese (Doutorado em Sociologia) - Universidade de São Paulo, 2007.

ABRAMO, Laís; RANGEL, Marta (Ed.). América Latina: negociación colectiva y equidad de género. Santiago de Chile: OIT, 2005.

ABRAMO, Laís; TODARO, Rosalba. Cuestionando un mito: costos laborales de hombres y mujeres en América Latina. Lima: OIT, 2002.

31 Essa articulação é extremamente relevante em um país como o Brasil, onde as desigualdades de gênero e raça constituem eixos estruturantes dos padrões de desigualdade social. 
AGENDE. O Brasil para todos e todas: proposta AGENDE para o Plano Plurianual 2004-2007: crescimento sustentável, emprego e inclusão social. Brasília (DF), 2003. (Cadernos Agende, v. 4).

BANDEIRA, Lourdes; VASCONCELOS, Marcia. Equidade de gênero e políticas públicas: relfexões iniciais. Brasília (DF), 2002. (Cadernos Agende, v. 3).

BERGER, S.; SZRETTTER, H. Costos laborales de hombres y mujeres. El caso de Argentina. In: ABRAMO, Laís; TODARO, Rosalba (Ed.). Cuestionando un mito: costos laborales de hombres y mujeres en América Latina. Lima: OIT, 2002. cap. 2.

BRASIL. Secretaria Especial de Políticas para as Mulheres (SPM). Plano Nacional de Políticas para as Mulheres. Brasília (DF), 2004a.

- Programa Pró-Equidade de Gênero: oportunidades iguais, respeito às diferenças. 2. ed. Brasília (DF), 2008.

. Pró-Equidade de Gênero: relatório sintético da $1^{\text {a }}$ edição (2005/2006). Brasilia (DF), 2006b. Disponível em: <http:/ /200.130.7.5/spmu/ docs/Pro-eq_1_relatorio.pdf>. Acesso em: 12 maio 2007.

- Relatório de implementação 2005: Plano Nacional de Políticas para as Mulheres. Brasília (DF), 2006a. Disponível em: $<$ http://200.130.7.5/spmu/docs/pnpm_relatorio.pdf $>$. Acesso em: $12 /$ maio/2007.

CASTILLO, Juan José. El absentismo laboral de la mujer: el fin de un mito. In: El trabajo del sociólogo. [Madrid]: Editorial Complutense, 1994. Cap. 15.

DEPARTAMENTO INTERSINDICAL DE ESTATÍSTICA E ESTUDOS SOCIOECONÔMICOS (Dieese). Negociação coletiva e equidade de gênero no Brasil: cláusulas relativas aos trabalhos da mulher no Brasil, 1996-2000. São Paulo, 2003. (Pesquisa DIEESE, n. 17).

FURNAS tem diretrizes de igualdade de gênero. Revista FURNAS, [Rio de Janeiro], v. 32, n. 331, p. 22-23, abr. 2006.

GEBRIM, Vera. Brasil: Negociación colectiva y equidad de género. In: ABRAMO, Laís; RANGEL, Marta. América Latina: negociación colectiva y equidad de género. Santiago de Chile: OIT, 2005. cap. 4. 
MONTAÑO, Sonia; PITANGUY, Jacqueline; LOBO, Theresa. As políticas públicas de gênero: um modelo para armar: o caso do Brasil. Santiago de Chile: CEPAL, 2003. (Serie mujer y desarrollo, n. 45). Disponível em: <http://www.eclac.cl/publicaciones/ xml/9/12689/lcl1920p.pdf>. Acesso em: 12 maio 2007.

Submetido em 15 setembro de 2008 e aceito em 4 de novembro de 2008 . 